\title{
The effect of surface conditioning on the bond strength of resin composite to amalgam
}

\author{
Blum, Igor R ; Hafiana, Khaula ; Curtis, Andrew ; Barbour, Michele E ; Attin, Thomas ; Lynch,
} Christopher D ; Jagger, Daryll C

\begin{abstract}
OBJECTIVES: This study evaluated the effect of different surface conditioning methods on the tensile bond strength (TBS) and integrity of the amalgam-resin composite interface, using commercially available restoration repair systems. METHODS: One hundred and sixty Gamma 2 amalgam specimens were stored in artificial saliva for 2 weeks and then randomly assigned to one of the following conditioning groups (n=20/group): Group 1: air abrasion, alloy primer and 'Panavia 21', Group 2: air abrasion and 'Amalgambond Plus', Group 3: air abrasion and 'All-Bond 3', Group 4: diamond bur, alloy primer and 'Panavia 21', Group 5: diamond bur and 'Amalgambond Plus', Group 6: diamond bur and 'All-Bond 3', Group 7: silica coating technique, and Group 8: non-conditioned amalgam surfaces (control group). Subsequently, resin composite material was added to the substrate surfaces and the amalgam-resin composite specimens were subjected to TBS testing. Representative samples from the test groups were subjected to scanning electron microscopy and surface profilometry. The data was analysed statistically with one-way ANOVA and post hoc Tukey's tests $(=0.05)$. RESULTS: The mean TBS of amalgam-resin composite ranged between 1.34 and $5.13 \mathrm{MPa}$ and varied with the degree of amalgam surface roughness and the type of conditioning technique employed. Significantly highest TBS values $(5.13 \pm 0.96 \mathrm{MPa})$ were obtained in Group $1(\mathrm{p}=0.013)$. CONCLUSION: Under the tested conditions, significantly greater tensile bond strength of resin composite to amalgam was achieved when the substrate surface was conditioned by air abrasion followed by the application of the Panavia 21 adhesive system. CLINICAL SIGNIFICANCE: Effecting a repair of an amalgam restoration with resin composite via the use of air abrasion and application of Panavia 21 would seem to enhance the integrity of the amalgam-resin composite interface. Clinical trials involving the implementation of this technique are indicated to determine the usefulness of this technique.
\end{abstract}

DOI: https://doi.org/10.1016/j.jdent.2011.10.019

Posted at the Zurich Open Repository and Archive, University of Zurich

ZORA URL: https://doi.org/10.5167/uzh-67443

Journal Article

Accepted Version

Originally published at:

Blum, Igor R; Hafiana, Khaula; Curtis, Andrew; Barbour, Michele E; Attin, Thomas; Lynch, Christopher D; Jagger, Daryll C (2012). The effect of surface conditioning on the bond strength of resin composite to amalgam. Journal of dentistry, 40(1):15-21.

DOI: https://doi.org/10.1016/j.jdent.2011.10.019 
The effect of surface conditioning on the bond strength of resin composite to amalgam

Igor R. Blum DDS, PhD, Dr Med Dent, MSc, MFDSRCS, PGCertHE University of Bristol Dental Hospital \& School, United Kingdom Khaula Hafiana DDS MSc

University of Bristol Dental Hospital \& School, United Kingdom Andrew Curtis PhD

Biomaterials Engineering Group, University of Bristol

Michele E. Barbour PhD

University of Bristol Dental Hospital \& School, United Kingdom Thomas Attin Dr Med Dent, Professor

University of Zürich, Center for Dental Medicine, Switzerland

CD Lynch

University of Bristol Dental Hospital \& School.

Daryll C. Jagger BDS, PhD, MSc, FDSRCS (Eng), FDS RCS (Rest Dent) University of Glasgow Dental Hospital \& School, United Kingdom 


\section{Abstract}

Objectives: This study evaluated the effect of different surface conditioning methods on the tensile bond strength (TBS) and integrity of the amalgam-resin composite interface, using commercially available restoration repair systems.

Methods: One hundred and sixty Gamma 2 amalgam specimens were stored in artificial saliva for 2 weeks and then randomly assigned to one of the following conditioning groups ( $n=20$ /group): Group 1: air abrasion, alloy primer and 'Panavia 21', Group 2: air abrasion and 'Amalgambond Plus', Group 3: air abrasion and 'All-Bond 3', Group 4: diamond bur, alloy primer and 'Panavia 21 ', Group 5: diamond bur and 'Amalgambond Plus', Group 6: diamond bur and 'All-Bond 3', Group 7: silica coating technique, and Group 8: nonconditioned amalgam surfaces (control group). Subsequently, resin composite material was added to the substrate surfaces and the amalgam -resin composite specimens were subjected to TBS testing. Representative samples from the test groups were subjected to scanning electron microscopy and surface profilometry. The data was analysed statistically with oneway ANOVA and post hoc Tukey's tests $(\mathrm{a}=0.05)$.

Results: The mean TBS of amalgam -resin ranged between 1.34 and 5.13 MPa and varied with the degree of amalgam surface roughness and the type of conditioning technique employed. Significantly highest TBS values $\left(5.13 \_0.96 \mathrm{MPa}\right)$ were obtained in Group 1 $(\mathrm{p}=0.013)$

Conclusion: Under the tested conditions, significantly greater tensile bond strength of resin composite to amalgam was achieved when the substrate surface was conditioned by air abrasion followed by the application of the Panavia 21 adhesive system.

Clinical significance: Effecting a repair of an amalgam restoration with resin composite via the use of air abrasion and application of Panavia 21 would seem to enhance the integrity of 
the amalgam-composite interface. Clinical trials involving the implementation of this technique are indicated to determine the usefulness of this technique.

\section{Introduction}

Replacement of defective amalgam restorations accounts for a substantial part of activity performed in general dental practice. ${ }^{1-3}$ The main reasons for replacement include secondary caries, marginal defects, inadequate marginal integrity or inadequate interproximal contact. ${ }^{4,5}$ Another common reason for amalgam replacement is partial or complete cusp fracture adjacent to, or involving, the amalgam restorations. ${ }^{6,7}$

Previous studies indicate that complete cusp fracture in teeth restored with amalgam restorations is a relatively common observation in clinical practice and particularly so for posterior teeth restored with extensive amalgam restorations. ${ }^{7-9}$ The prevalence of complete cusp fracture in amalgam-restored premolar and molar teeth has been reported to range between $4-8 \%$ and 5-15\% respectively. ${ }^{10-13}$ The majority of cusp fractures are observed in, and limited to, the supra-gingival location, which suggests that the fractured tooth is amenable to restorative procedures. ${ }^{12}$ Various factors may contribute to cusp fracture of amalgam-restored teeth, including lack of adhesion of amalgam to tooth structures, thereby providing no significant change in the fracture resistance of the cusps ${ }^{14}$ or in the amount of cuspal flexure $^{15}$ relative to equivalent unrestored teeth. These factors may be compounded by the presence of undermined cusps, extensive restoration size, parafunctional activity, impact load, fatigue load, and occlusal disharmony. ${ }^{9}$ 
The traditional approach to the management of cusp fractures in teeth which have been restored with amalgam has been either total restoration replacement resulting in more extensive direct restorations, or preparation for indirect restorations. Both of these procedures result in increased preparation and restoration size. ${ }^{16}$ This approach has been referred to as the "repetitive restoration cycle ${ }^{17}$ and can result in the progressive weakening of the tooth through unnecessary removal of sound tooth tissue, detrimental effects on the dental pulp, together with potential damage caused to adjacent teeth. ${ }^{18}$

Whilst some amalgam restorations with adjacent cusp fracture, notably those associated with an extensive secondary caries lesion, will inevitably require replacement, it may be suggested that some amalgam restorations with adjacent cusp fracture may be given extended longevity through repair procedures (i.e. cusp replacement with or without partial replacement of the amalgam restoration, allowing preservation of that portion of the restoration that presents no clinical or radiographic evidence of failure). This more conservative minimally intervention approach to the management of cusp fracture adjacent to or involving the amalgam restoration, offers many advantages, including:

- more conservative of tooth tissue,

- reduced risk of iatrogenic damage,

- $\quad$ reduced need for the use of local anaesthesia,

- opportunity for enhanced patient experience,

- savings in time and resources.

In contrast to amalgam repair procedures using bonded amalgam, the use of composite resin as a repair material provides additional aesthetic and structural benefits. This is attributable to 
the improved appearance owing to veneering of the amalgam with tooth-coloured restorative material, and adhesion of the composite resin to remaining tooth tissue, resulting in strengthening of the tooth-material interface. ${ }^{19}$

An important aspect related to the quality of amalgam repair is the quality of the interfacial bond between amalgam and composite resin repair material. In consideration of continuous advances in adhesive and composite resin material technology as well as the drive towards the principles of minimally invasive dentistry, a growing number of commercially available intra - oral restoration repair systems for the direct veneering of amalgam have been introduced to the market. However, despite the ever increasing number of these repair systems, the literature is sparse regarding the best protocol for performing an amalgam repair using composite resin.

The primary aim of this in vitro study was to evaluate the effects of different amalgam surface conditioning methods on the tensile bond strength (TBS) between amalgam and a nanohybrid composite resin restorative material, using various intra-oral restoration repair systems. The secondary aim was to the nature of interfacial failure, using scanning electron microscopy (SEM) and profilometry examinations of failed interfacial surfaces. The null hypothesis tested was that of no statistical difference in repair bond strengths between the various repair protocols. 


\section{Materials and methods}

\section{Specimen preparation}

One hundred and sixty poly(methymethacrylate) (PMMA) retention bases (Mould 1) (VisionTek Systems Ltd., Chester, UK) were prepared containing a central recess (width $5 \mathrm{~mm}$, height $5 \mathrm{~mm}$, depth $4 \mathrm{~mm}$ ). A cavity of $2 \mathrm{~mm}$ diameter and $2 \mathrm{~mm}$ depth was prepared at the base of this central recess, to facilitate mechanical retention of the amalgam. The amalgam (non-gamma 2, lathe-cut, high-copper alloy with 43\% Ag, 25.4\% Cu) (ANA 2000 Duet, Nordiska Dental AB, Angelholm, Sweden) was triturated according to the manufacturer's instructions and then condensed with a hand instrument into the recess within the PMMA base. Specimens were allowed to set for $24 \mathrm{~h}$ at $23.0 \pm 1.0^{\circ} \mathrm{C}$ and were subsequently polished with a wet 1200-grit silicon carbide disc (Struers RotoPol 11, Struers $\mathrm{A} / \mathrm{S}$, Rodovre, Denmark) at $300 \mathrm{rpm}$ for $30 \mathrm{~s}$ and cleaned for 10 minutes in an ultrasonic bath (Quantrex 90 WT, L\&R Manufacturing Inc., Kearny, NJ, USA) containing deionised water to eliminate possible contaminants. All specimens were then air - dried $\left(23.0 \pm 1.0^{\circ} \mathrm{C}\right)$ for 24 hours and subsequently stored in artificial saliva for 2 weeks at $37.0 \pm 1.0{ }^{\circ} \mathrm{C}$ to represent an aging process.

\section{Surface conditioning methods}

The PMMA/amalgam specimens were randomly divided into eight groups, each containing 20 specimens to receive the following surface conditioning treatments according to the manufacturers' instructions:

Group 1: Air-borne particle abrasion with $50 \mu \mathrm{m} \mathrm{Al}{ }_{2} \mathrm{O}_{3}$ (Korox R, Bego, Bremen, Germany) using an intraoral sandblaster (Dento-PrepTM, RØNVIG A/S, Daugaard, Denmark) from a 
distance of $10 \mathrm{~mm}$ at a pressure of 2.5 bar for $4 \mathrm{~s}$ followed by application of Alloy primer (Kuraray, Japan) and Panavia 21 (Kuraray, Japan).

Group 2: Air-borne particle abrasion as for group 1 followed by application of Amalgambond Plus (Parkell, USA).

Group 3: Air-borne particle abrasion as for group 1 followed by application of ALL-BOND 3 (Bisco, USA).

Group 4: Surface roughening with a diamond bur (Classic Diamond \#521M, Dental Directory, Essex, UK) for $10 \mathrm{~s}$ and application of Alloy primer (Kuraray, Japan) and Panavia 21 (Kuraray, Japan).

Group 5: Diamond bur roughening as for group 4 followed by application of Amalgambond Plus (Parkell, USA).

Group 6: Diamond bur roughening as for group 4 followed by application of ALL-BOND 3 (Bisco, USA).

Group 7: Silica coating with $30 \mu \mathrm{m} \mathrm{SiO}_{2}$ particles using an intraoral sandblaster (3M ESPE, Germany) from a distance of $10 \mathrm{~mm}$ at a pressure of 2.5 bar for $4 \mathrm{~s}$ followed by application of the corresponding silane and bonding agents (ESPE-Sil and Visio-bond) of the CoJet System (3M ESPE, Germany).

Group 8 (control group): No surface conditioning and no adhesive system was used.

The description, composition and manufacturers of the intra-oral adhesive repair systems used in this study are summarised in Table 1. 


\section{Repair composite resin application}

An additional 160 PMMA retention bases, were prepared and used for the composite resin application procedure (Mould 2). These PMMA bases contained a recess for the composite resin material. Mould 2 was placed onto the surface of conditioned amalgam specimens (Mould 1). A nanohybrid composite resin material (NANOSIT ${ }^{\mathrm{TM}}$, Nordiska Dental AB, Angelholm, Sweden) was packed against the amalgam with a composite-filling instrument in $2 \mathrm{~mm}$ increments and polymerized with a standardised visible light curing unit (Smartlite ${ }^{\mathrm{TM}}$ PS, Dentsply, Germany) for $40 \mathrm{~s}$, operating at a measured output of $680 \mathrm{~mW} / \mathrm{cm}^{2}$ intensity. All surface treatment and repair procedures were performed by a single experienced operator in accordance with the manufacturers' instructions. Following light polymerisation, all amalgam/composite resin specimens were stored for 24 hours at $23.0 \pm 1.0{ }^{\circ} \mathrm{C}$ room temperature before being subjected to tensile bond strength testing.

\section{Tensile testing}

The PMMA moulds retaining the amalgam-composite resin specimens were mounted on a universal testing machine (Lloyd Instruments Ltd. Model LR5K, Hampshire, UK) fitted with a $1 \mathrm{kN}$ load cell, travelling at a crosshead speed of $0.5 \mathrm{~mm} / \mathrm{min}$. A tensile force was applied until failure occurred. The data were subjected to statistical analysis using a one-way analysis of variance and post-hoc Tukey test.

\section{Failure analysis}

The surfaces of three randomly selected specimens from each test group were examined under SEM to investigate the surface morphology of the failed surfaces. The specimens were sputter coated with a $15 \mathrm{~nm}$ layer of Pt/Pd to aid conductivity and examined using a Jeol JSM 
$5600 \mathrm{LV}$ SEM (Jeol Ltd., Japan) at an operating voltage of $15 \mathrm{kV}$ in the secondary electron mode. Failures were classified as adhesive, cohesive or mixed. Adhesive failure was defined as a complete debonding of the adhesive system from the treated amalgam surface (adherent). Cohesive failure was defined as a fracture that occurred in the composite resin and showed remnants of bonding agent or composite resin on both sides. Mixed failure was defined as a fracture that showed evidence of adhesive and cohesive failures.

The failed surfaces of another three randomly selected specimens from each test group were examined under three-dimensional profilometry to examine the surface roughness profiles at the failed surfaces. The surface roughness profile value $\left(R_{\mathrm{a}}\right.$-value $)$ of amalgam specimens $(n=3)$ from each group following failure was determined using three-dimensional profilometry (ProScan-2000; Scantron Industrial Products, Ltd., UK). Scanning was conducted over a $4.0 \times 3.0 \mathrm{~mm}$ area with an $\mathrm{x}$ and y step-size of 0.01 and $0.10 \mathrm{~mm}$ and number of steps of 400 and 30, respectively. 


\section{Results}

\section{Bond Strength}

The results of the tensile bond strength tests are presented in Table 2.

The tensile strength of all of the specimens in the control group (without mechanical and adhesive surface conditioning) was zero (no adhesion).

Surface conditioning with alumina sandblasting and the use of Alloy primer and Panavia 21 resulted in significantly higher bond strength values $(5.13 \pm 0.57 \mathrm{MPa})$ than all other surface conditioning methods $(\mathrm{p}=0.013)$. The bond strength values of specimens treated with Allbond 3 presented significantly lower bond strength values compared to other conditioning methods where alumina sandblasting was used $(\mathrm{p}=0.02)$. No significant difference in bond strength values was noted between the alumina sandblasting together with the use of All Bond 3 protocol and for conditioning methods involving bur roughening of the amalgam surface.

There was no significant difference between the bond strength values of specimens prepared with the CoJet system $(3.72 \pm 0.51 \mathrm{MPa})$, diamond bur-Panavia system $(3.42 \pm 0.35 \mathrm{MPa})$ or diamond bur-Amalgambond Plus (3.40 $\pm 0.66 \mathrm{MPa})$. 


\section{Failure Analysis}

SEM examination showed that all specimens examined failed adhesively, irrespective of the repair protocol used. A summary of the mean surface roughness values ( $R_{a}$-values) is shown in Table 3. The surface roughness of specimens, as highlighted by the $R_{a}$-values determined by three-dimensional profilometry, identified that the roughness of specimens prepared by alumina sandblasting (mean $R a=3.56 \mu \mathrm{m}$ ) was markedly less than where a diamond bur (mean $R a=15.35 \mu \mathrm{m}$ ) was used. The use of CoJet silicatization produced the lowest surface roughness $\left(R_{a}=1.95 \mu \mathrm{m}\right)$. 


\section{Discussion}

Repairing an amalgam restored tooth exhibiting signs of single or multiple cusp fractures can result in extended longevity of the existing restoration without unnecessarily sacrificing healthy tooth structure as a result of progressive tooth preparation, and reducing the risk of pulpal damage. ${ }^{2}$ It is clearly preferable, therefore, to consider a repair procedure as an alternative to total restoration replacement or tooth preparation for a cast restoration, wherever possible. Since the repair of amalgam restorations with amalgam has been reported to be unreliable, it has been suggested that alternative techniques need to be explored. ${ }^{9,20}$ In the case of cusp fracture in teeth restored with amalgam it is often aesthetically favourable to veneer the amalgam with a tooth-coloured material, with the potential advantage of bonding to the surrounding tooth tissue, offering cuspal replacement and possible reinforcement

This study was undertaken to evaluate the effect of different intra-oral adhesive repair systems and surface treatments on the integrity of the amalgam-composite resin interface. An important factor in the quality of amalgam repair is the interfacial bond between the joined surfaces. Although in vitro investigations cannot be directly translated to the in vivo situation they are of benefit and can be a useful predictor of the potential clinical performance of a material.

Previous studies of interfacial bond strength of repaired amalgam have evaluated the interfacial shear bond strength. ${ }^{9,21}$ Shear bond strength testing has limitations, since shear

stress is not uniformly distributed across and not necessarily focused at the true interface. ${ }^{22,23}$ This may partly explain the higher interfacial bond strengths observed with shear testing when compared to tensile testing, when all testing variables (i.e. specimen geometry, adhesive film thickness, and modulus of elasticity of the materials involved) remain constant. Furthermore, shear test data has been reported to show high coefficients of variation. This 
has been attributed to the non-uniform stresses generated with shear testing within the interfacial zone as this can have a significant effect on the mode of failure. ${ }^{24}$

The basis for selection of the adhesive repair systems used in the current study was their demonstrated ability to bond to metals ${ }^{25}$, their use in similar studies involving amalgam ${ }^{6,9,21,26}$ and their commercial availability as products marketed for facilitating intra-oral amalgam repairs.

It is difficult to make direct comparisons with the results of other studies due to differences in methodology used. The results of the tensile bond strength tests after surface conditioning with sandblasting followed by Panavia adhesive system yielded superior results compared to the other conditioning protocols used in the current study. Thus, the null hypothesis has to be rejected.

In contrast to a previous study ${ }^{20}$, the findings of the current study indicate that surface roughness of the amalgam substrate appears to have a significant influence on its repair bond strength. Alumina sandblasting and silicatization are surface treatments that cause "micro" retentive features, while a diamond bur yields "macro" and "micro" retentive features. Without the use of an adhesive system, greater repair strength may be anticipated from substrates yielding macro-retentive features. On the other hand, with the use of adhesive agents, a better surface wetting was found to occur with the micro-retentive amalgam surfaces, probably due to better infiltration and improved physical interlocking of the layers of the adhesive agent within the micro-retentive amalgam surfaces. However, excessive mechanical abrasion has been reported to induce defect centres from which crack propagation and failure of the adhesive interface may occur. ${ }^{27-29}$

The comparatively mild mechanical surface effects of alumina sandblasting and silicatization remove large surface asperities and provide a more homogeneous surface with major defects 
and stress concentrations removed; thereby providing a relatively uniformly roughened surface with a low $R a$-value for the application of the adhesive agent and composite resin veneer. In contrast, the high degree of roughening observed $(13.5-16.6 \mu \mathrm{m})$ induced by treatment with the diamond bur is likely to have induced surface defects and areas of stress concentration as well as deep asperities into which the adhesive agent may not have fully penetrated, resulting in a weaker interfacial bond. Previous studies have highlighted higher interfacial bond strengths between amalgams and composite resins where low surface roughness values were induced compared with higher values induced by treatment with carbide burs. ${ }^{9,30-32}$

In this study a lower surface roughness induced by alumina sandblasting in combination with the Panavia adhesive system, resulted in a significantly higher tensile bond strength compared with specimens treated with the Panavia adhesive system but prepared with a diamond bur, resulting in a markedly greater surface roughness. This may suggest that the improved surface homogeneity implicit in the removal of large surface defects associated with alumina sandblasting enabled an improved adhesive bond to be formed between the two surfaces owing to the absence of large surface defects such as those produced as a result of preparation with the bur. The tensile bond strength values observed with the CoJet system may be attributable to the low surface roughness produced by silicatization and may be a further indication for the importance of a homogeneous substrate surface to facilitate interfacial adhesive bonds to develop. 


\section{Conclusions}

Within the limitations of this study, it appears that :

1. The tensile bond strengths of composite resin to amalgam varied with the degree of amalgam surface roughness and the type of conditioning technique employed.

2. The combination of alumina sandblasting of the amalgam surface followed by the application of the Panavia adhesive system exhibited significantly higher tensile bond strengths than other repair protocols tested.

3. Interfacial failure between amalgam and composite resin was of adhesive nature, irrespective of the repair protocol employed. 


\section{References}

1. Mjör IA, Moorhead JE \& Dahl JE (2000) Reasons for replacement of restorations in permanent teeth in general dental practice International Dental Journal 50(6) 361366.

2. Tyas MJ, Anusavice KJ, Frencken JE \& Mount GJ (2000) Minimal intervention dentistry - a review FDI Commission Project 1-97 International Dental Journal 50(1) $1-12$.

3. Jokstad A, Bayne SC, Blunck U, Tyas MJ \& Wilson NHF (2001) Quality of dental restorations. FDI Commission Project 2-95 International Dental Journal 51(3) 117158.

4. Hickel R \& Manhart J (2001) Longevity of restorations in posterior teeth and reasons for failure Journal of Adhesive Dentistry 3(1) 45-64.

5. Moncada G, Fernandez E, Martin J, Arancibia C, Mjör I \& Gordan VV (2008) Increasing the longevity of restorations by minimal intervention: A two-year clinical trial Operative Dentistry 33(3) 258-264.

6. Cehreli SB, Arhun N \& Celik C (2010) Amalgam repair: quantitative evaluation of amalgam-resin and resin-tooth interfaces with different surface treatments Operative Dentistry 35(3) 337-344

7. Özcan M, Schoonbeek G, Gökçe B, Cömlekoglu E \& Dündar M (2010) Bond strength comparison of amalgam repair protocols using composite resin in situations with and without dentin exposure Operative Dentistry 35(6) 655-662.

8. Pilo R, Brosh T \& Chweidana H (1998) Cusp reinforcement by bonding of amalgam restorations Journal of Dentistry 26(5) 467-472 
9. Özcan M, Vallittu PK, Huysmans M.-C., Kalk W \& Vahlberg T (2006) Bond strength of composite resin to differently conditioned amalgam Journal of Materials Science: Materials in Medicine 17(1) 7- 13

10. Bader JD, Martin JA \& Shugars DA (1995) Preliminary estimates of the incidence and consequence of tooth fracture Journal of the American Dental Association 126(12) $1650-1654$.

11. Heft HW, Gilbert GH, Dolan TA \& Foerster U (2000) Restoration fractures, cusp fractures and root fragments in a diverse sample of adults: 24 month incidence. Journal of the American Dental Association 131(10) 1459-1464.

12. Fennis WM, Kuijs RH, Kreulen CM, Roeters FJ, Creugers NH \& Burgersdijk RC (2002) A survey of cusp fractures in a population of general dental practices International Journal of Prosthodontics 15(6) 559-563

13. Van Nieuwenhuysen JP, D'Hoore W, Carvalho J \& Qvist V (2003) Long-term evaluation of extensive restorations in permanent teeth Journal of Dentistry 31(6) $395-405$.

14. Boyer DB \& Roth L (1994) Fracture resistance of teeth with bonded amalgams American Journal of Dentistry 7(2) 91-94.

15. Linn J \& Messer HH (1994) Effect of restorative procedures on the strength of endodontically treated molars Journal of Endodontics 20(10) 479-485.

16. Gordan VV, Shen C \& Mjör IA (2004) Marginal gap repair with flowable resin based composites General Dentistry 52(5) 390-394. 
17. Elderton RJ (1997) Changing the course of dental education to meet future requirements Journal of the Canadian Dental Association 63(8) 633-639.

18. Tyas MJ (2005) Placement and replacement of restorations by selected practitioners Australian Dental Journal 50(2) 81-89.

19. Ruse ND, Sekimoto RT \& Feduik D (1995) The effect of amalgam surface preparation on shear bond strength between composite and amalgam Operative Dentistry 20(5) 180-185.

20. Giannini M, Paulillo LA \& Ambrosano GM (2002) Effect of Surface Roughness on Amalgam Repair Using Adhesive Systems Brazilian Dental Journal 13(3) 179-183

21. Roggenkamp CL, Berry FA \& Lu H (2010) In vitro bond strengths of amalgam added to existing amalgams Operative Dentistry 35(3) 314-323.

22. Salz U \& Bock T (2010) Testing adhesion of direct restoratives to dental hard tissue a review Journal of Adhesive Dentistry 12(5) 343-371.

23. Van Meerbeek B, Peumans M, Poitevin A, Mine A, Van Ende A, Neves A \& De Munck J (2010) Relationship between bond-strength tests and clinical outcomes Dental Materials 26(2) e100-121.

24. Scherrer SS, Cesar PF \& Swain MV Direct comparison of the bond strength results of the different test methods: a critical literature review Dental Materials 26(2) e78-93.

25. Omura I, Yamauchi J, Harada I \& Wada T (1984) Adhesive and mechanical properties of a new dental adhesive Journal of Dental Research 63 (Supplement 1) Abstract \#561 p 233.

26. Garcia-Barbero AE, Garcia-Barbero J \& Lopez-Calvo JA (1994) Bonding of amalgam to composite: tensile and morphology study Dental Materials 10(2) 83-87. 
27. Lubow RM \& Cooley RL (1986) Effect of air-powder abrasive instrument on restorative materials Journal of Prosthetic Dentistry 55(4) 462-465.

28. Goldstein RE \& Parkins FM (1994) Air-abrasive technology: its new role in restorative dentistry Journal of the American Dental Association 125(5) 551-557.

29. Lim BS, Heo SM, Lee YK \& Kim CW (2003) Shear bond strength between titanium alloys and composite resin: sandblasting versus fluoride-gel treatment Journal of Biomedical Materials Research Part B: Applied Biomaterials 64(1) 38-43.

30. Fruits TJ, Duncanson MG \& Coury TL (1998) Interfacial bond strength of amalgam bonded to amalgam and composite resin bonded to amalgam Quintessence International 29(5) 327-334.

31. Al-Jazairy YH (2001) Shear peel bond strength of compomers veneered to amalgam Journal of Prosthetic Dentistry 85(4) 396-400.

32. Machado C, Sanchez E, Alapati S, Seghi R \& Johnston W (2007) Shear bond strength of the amalgam-resin composite interface Operative Dentistry 32(4) 341-346. 
Table 1. Description, composition and manufacturers of the intra-oral adhesive repair systems and composite resin material used in this study

\begin{tabular}{|c|c|c|c|}
\hline Material & $\begin{array}{c}\text { Material } \\
\text { description }\end{array}$ & Chemical composition & Manufacturer \\
\hline $\begin{array}{l}\text { Alloy Primer }+ \\
\text { Panavia } 21\end{array}$ & $\begin{array}{l}\text { Metal conditioning } \\
\text { primer }+ \\
\text { dual-cure adhesive } \\
\text { system }\end{array}$ & $\begin{array}{l}\text { Primer: 6-[(4-vinylbenzyl)propylamino]- } \\
\text { 1,3,5- Itriazine-2,4-dithione (VBATDT), } \\
\text { 10-Methacryloyloxydecyl dihydrogen } \\
\text { phosphate (MDP adhesive monomer) } \\
\text { Adhesive system: } \\
\text { 10-methacryloyloxydecyl dihydrogen } \\
\text { phosphate, dimethacrylate, silica filler }\end{array}$ & $\begin{array}{l}\text { Kuraray, } \\
\text { Okayama, Japan }\end{array}$ \\
\hline $\begin{array}{l}\text { Amalgambond } \\
\text { Plus }\end{array}$ & $\begin{array}{l}\text { Self-cure etch \& } \\
\text { rinse adhesive } \\
\text { system }\end{array}$ & $\begin{array}{l}\text { META (4-methacryloxyethyl trimellitate } \\
\text { anhydride), bisphenol-A-dimethyacrlate, } \\
\text { HEMA (hydroxyethyl methacrylate), } \\
\text { ethylene glycol methacrylate }\end{array}$ & Parkell, Parrmingdale, II, ISI \\
\hline ALL-BOND 3 & $\begin{array}{l}\text { Dual-cure etch \& } \\
\text { rinse universal } \\
\text { adhesive system }\end{array}$ & $\begin{array}{l}\text { BisGMA (Bisphenol-A-dimethyacrlate), } \\
\text { urethane dimethacrylate, triethylene glycol } \\
\text { dimethacrylate, silica filler }\end{array}$ & $\begin{array}{l}\text { Bisco, Inc } \\
\text { Schaumburg, IL, } \\
\text { USA }\end{array}$ \\
\hline CoJet-Sand & $\begin{array}{l}\text { Sand for coating } \\
\text { substrate surface }\end{array}$ & $\begin{array}{l}\text { Aluminium trioxide particles coated with } \\
\text { silica, particles size: } 30 \mu \mathrm{m}\end{array}$ & $\begin{array}{l}\text { 3M ESPE AG, } \\
\text { Seefeld, Germany }\end{array}$ \\
\hline ESPE-Sil & $\begin{array}{l}\text { Silane coupling } \\
\text { agent }\end{array}$ & $\begin{array}{l}\text { 3-methacryloxypropyltrimethoxysilane, } \\
\text { ethanol }\end{array}$ & $\begin{array}{l}\text { 3M ESPE AG, } \\
\text { Seefeld, Germany }\end{array}$ \\
\hline Visio-bond & $\begin{array}{l}\text { Adhesive bonding } \\
\text { agent }\end{array}$ & $\begin{array}{l}\text { Bisacrylate, aminodiol methacrylate, } \\
\text { camphor-quinone, benzyl dimethyl ketale, } \\
\text { stabilisers }\end{array}$ & $\begin{array}{l}\text { 3M ESPE AG, } \\
\text { Seefeld, Germany }\end{array}$ \\
\hline NANOSIT & $\begin{array}{l}\text { Nano-hybrid } \\
\text { composite resin } \\
\text { restorative material }\end{array}$ & $\begin{array}{l}\text { BisGMA (bisphenol-A-dimethyacrylate), } \\
\text { HEMA (hydroethyl dimethacrylate), } \\
\text { inorganic glass particles ( } 57 \mathrm{vol} \% ; 74 \mathrm{wt} \%) \text {, } \\
\text { particle size: } 2.0-0.2 \mu \mathrm{m}\end{array}$ & $\begin{array}{l}\text { Nordiska Dental } \\
\text { AB, Angelholm, } \\
\text { Sweden }\end{array}$ \\
\hline
\end{tabular}


Table 2. Amalgam surface repair protocols based on testing groups ( $n=20$ per group)

\begin{tabular}{|c|c|c|c|c|c|c|c|c|}
\hline $\begin{array}{l}\text { Surface } \\
\text { conditioning } \\
\text { method }\end{array}$ & $\begin{array}{c}\text { Group } \\
1\end{array}$ & $\begin{array}{l}\text { Group } \\
2\end{array}$ & $\begin{array}{l}\text { Group } \\
\quad 3\end{array}$ & $\underset{4}{\text { Group }}$ & $\begin{array}{l}\text { Group } \\
5\end{array}$ & $\begin{array}{c}\text { Group } \\
6\end{array}$ & $\begin{array}{c}\text { Group } \\
7\end{array}$ & $\begin{array}{l}\text { Group } \\
\quad 8\end{array}$ \\
\hline $\begin{array}{l}\text { Air particle } \\
\text { abrasion with } \\
\mathrm{Al}_{2} \mathrm{O}_{3} \\
(50 \mu \mathrm{m})\end{array}$ & $\sqrt{ }$ & $\sqrt{ }$ & $\sqrt{ }$ & & & & & \\
\hline $\begin{array}{l}\text { Tungsten carbide } \\
\text { bur }\end{array}$ & & & & $\sqrt{ }$ & $\sqrt{ }$ & $\sqrt{ }$ & & \\
\hline $\begin{array}{l}\text { Alloy Primer + } \\
\text { Clearfil SE }\end{array}$ & $\sqrt{ }$ & & & $\sqrt{ }$ & & & & \\
\hline $\begin{array}{l}\text { Amalgambond } \\
\text { Plus }\end{array}$ & & $\sqrt{ }$ & & & $\sqrt{ }$ & & & \\
\hline All Bond 3 & & & $\sqrt{ }$ & & & $\sqrt{ }$ & & \\
\hline $\begin{array}{l}\text { Silica coating } \\
\text { (Silicatization) } \\
\left(\text { CoJet }{ }^{\circledR}-\text { Sand, }\right. \\
\left.30 \mu \mathrm{miO}_{2}\right)\end{array}$ & & & & & & & $\sqrt{ }$ & \\
\hline Composite resin & $\sqrt{ }$ & $\sqrt{ }$ & $\sqrt{ }$ & $\sqrt{ }$ & $\sqrt{ }$ & $\sqrt{ }$ & $\sqrt{ }$ & $\sqrt{ }$ \\
\hline
\end{tabular}


Table 3. Comparison of mean tensile bond strengths (TBS) and surface roughness values between repair protocols.

\begin{tabular}{|l|c||c|c|c|}
\hline $\begin{array}{l}\text { Surface } \\
\text { conditioning } \\
\text { method }\end{array}$ & $\begin{array}{c}\text { TBS } \\
\text { (SD) [MPa] }\end{array}$ & $\begin{array}{c}\text { 95\% Confidence } \\
\text { Intervals } \\
\text { (MPa) }\end{array}$ & $\begin{array}{c}\text { Statistical } \\
\text { groupings }\end{array}$ & $\begin{array}{c}\text { Ra-value } \\
(\boldsymbol{\mu m})\end{array}$ \\
\hline $\begin{array}{l}\text { Alumina sandblasting + } \\
\text { Alloy Primer + Panavia 21 }\end{array}$ & $5.13(0.96)$ & $5.71-4.58$ & $\mathrm{~d}$ & 4.76 \\
\hline $\begin{array}{l}\text { Alumina sandblasting + } \\
\text { Amalgambond Plus }\end{array}$ & $2.51(2.73)$ & $3.72-1.27$ & $\mathrm{c}$ & 3.58 \\
\hline $\begin{array}{l}\text { Alumina sandblasting + All } \\
\text { Bond 3 }\end{array}$ & $2.42(0.76)$ & $2.87-1.99$ & $\mathrm{a}, \mathrm{b}$ & 2.35 \\
\hline $\begin{array}{l}\text { Diamond bur + Alloy } \\
\text { Primer + Panavia 21 }\end{array}$ & $3.42(0.82)$ & $3.78-3.09$ & $\mathrm{~b}, \mathrm{c}$ & 16.56 \\
\hline $\begin{array}{l}\text { Diamond bur + } \\
\text { Amalgambond Plus }\end{array}$ & $3.40(1.68)$ & $4.06-2.75$ & $\mathrm{~b}, \mathrm{c}$ & 16.03 \\
\hline $\begin{array}{l}\text { Diamond bur + All Bond 3 } \\
\text { Silica coating } \\
\text { CoJet -system) }\end{array}$ & $1.34(0.71)$ & $1.60-1.10$ & $\mathrm{a}$ & 13.46 \\
\hline
\end{tabular}

*Lower case letters indicate statistically homogeneous groups. If two data sets share the same letter, they do not differ to a statistically significant degree. 